\title{
Evidence That the Primary Binding Site of von Willebrand Factor That Mediates Platelet Adhesion on Subendothelium Is Not Collagen
}

\author{
Philip G. de Groot, Mieke Ottenhof-Rovers, Jan A. van Mourik, ${ }^{\star}$ and Jan J. Sixma \\ Department of Hematology, University Hospital Utrecht, Utrecht, The Netherlands; and *Department of Blood Coagulation, \\ Central Laboratory of the Netherlands Red Cross Blood Transfusion Service, Amsterdam, The Netherlands
}

\begin{abstract}
We have studied the binding of von Willebrand factor to extracellular matrices of endothelial cells and to the vessel wall of human umbilical arteries in relation to its function in supporting platelet adhesion. CLB-RAg 201, an MAb against von Willebrand factor, completely inhibits the binding of von Willebrand factor to collagen type I and type III. CLB-RAg 201 does not inhibit the binding of ${ }^{125}$ I-von Willebrand factor to extracellular matrices of endothelial cells, to smooth muscle cells, or to the subendothelium. CLB-RAg 201 partly inhibits platelet adhesion to these surfaces, but this directly affects the interaction between von Willebrand factor and platelets and is not due to inhibition of binding of von Willebrand factor to these surfaces.
\end{abstract}

Another MAb, CLB-RAg 38, does not inhibit the binding of von Willebrand factor to collagen. CLB-RAg 38 completely inhibits the binding of von Willebrand factor to extracellular matrices. CLB-RAg 38 inhibits platelet adhesion to cellular matrices completely insofar as it is dependent on plasma von Willebrand factor. CLB-RAg 38 does not inhibit the total binding of von Willebrand factor to subendothelium, as there are too many different binding sites, but it completely inhibits the functional binding sites for von Willebrand factor that support platelet adhesion.

The epitopes for CLB-RAg 38 and 201 on the von Willebrand factor molecule are located on different fragments of the molecule. These results indicate that von Willebrand factor binds to subendothelium and matrices of cultured cells by a mechanism that is different from that by which it binds to collagen.

\section{Introduction}

Adherence of blood platelets at the site of vascular injury is a crucial step in the early phase of hemostasis (1), thrombogenesis (2), and atherogenesis (3). At high wall shear rates, platelet adherence is completely dependent on the presence of von Willebrand factor $(4,5)$. Experiments with reconstituted blood have shown that von Willebrand factor is the only plasma protein necessary for the adherence of platelets to human artery subendothelium (6). von Willebrand factor is present in

Address all correspondence to Dr. Philip G. de Groot, University Hospital Utrecht, Department of Hematology, P.O. Box 16250, 3500 CG Utrecht, The Netherlands.

Received for publication 18 September 1985 and in revised form 5 January 1988.

J. Clin. Invest.

(c) The American Society for Clinical Investigation, Inc.

0021-9738/88/07/0065/09 \$2.00

Volume 82, July $1988,65-73$ plasma, blood platelets, and the vessel wall. Endothelial cells are able to synthesize von Willebrand factor (7). Besides secreting it into the medium, they also deposit it in their extracellular matrix (8). The von Willebrand factor that is present in the subendothelium can support platelet adherence but plasma von Willebrand factor is necessary for optimal adhesion (5).

The binding of plasma von Willebrand factor precedes the adherence of platelets (6). Several groups of investigators have demonstrated that von Willebrand factor binds to collagen types I and III (9-14), and exposed collagen at the site of vessel injury has been considered to be involved in the binding of von Willebrand factor. Recently, Hormia et al. and Wagner et al. $(15,16)$ have suggested that not collagen but fibronectin may be the binding site of von Willebrand factor.

We have used a panel of MAbs directed against von Willebrand factor to study the structure-function relationships of von Willebrand factor $(5,14,17)$. We have found two MAbs that cause complete inhibition of platelet adherence at high shear rate (17). This inhibition went together with the inhibition of ristocetin-induced platelet aggregation and inhibition of binding of von Willebrand factor to platelets induced by ristocetin. We also described a second MAb that caused partial inhibition of platelet adhesion and which was found to inhibit the binding of von Willebrand factor to purified collagen (14). However, this MAb did not inhibit the binding of von Willebrand factor to subendothelium. To investigate this unexpected finding, we have tested other MAbs for their ability to inhibit binding of von Willebrand factor to subendothelium and to extracellular matrices of cultured smooth muscle cells and endothelial cells.

Here we describe that the binding of von Willebrand factor to extracellular matrices is completely inhibited by an MAb antibody to von Willebrand factor, CLB-RAg 38. CLB-RAg 38 also totally inhibits the adhesion of platelets at high shear rate under conditions in which adhesion is dependent only on plasma von Willebrand factor. CLB-RAg 38 does not inhibit the binding of von Willebrand factor to purified collagen. These results suggest that collagen is not the primary binding site for von Willebrand factor in the vessel wall.

\section{Methods}

Cell cultures. Human vascular endothelial cells were isolated from umbilical cords according to Jaffe et al. (18) with some minor modifications (19). The cells were cultured in a medium consisting of RPMI 1640 (Gibco, Paisley, U.K.) and 20\% pooled human serum. After confluence, the cells were subcultured $\left(2 \times 10^{4}\right.$ cells $\left./ \mathrm{cm}^{2}\right)$ on gelatincoated glass coverslips. After 5-7 d, when the cells reached confluence $\left(8-10 \times 10^{4} \mathrm{cells} / \mathrm{cm}^{2}\right)$, the cultures were exposed to $0.1 \mathrm{M} \mathrm{NH}_{4} \mathrm{OH}$ for $30 \mathrm{~min}$ at room temperature with gentle shaking. The cell layer was completely removed by this procedure, leaving the underlying extracellular matrix intact, homogeneously and firmly attached to the glass (20). The coverslips were used for experiments on the same day. 
Smooth muscle cells were isolated by outgrowth of explants from human umbilical arteries according to the method of Ross (21). After 4 wk, a confluent layer of cells was observed. They were identified by their typical growth pattern and formation of multilayers in culture (21). The smooth muscle cells were cultured in the same culture medium and subcultured as described for the endothelial cells. The extracellular matrix of smooth muscle cells was isolated at the moment that the cells completely covered the glass coverslip, just before multilayers of cells appeared.

For binding studies of ${ }^{125} \mathrm{I}$-von Willebrand factor to extracellular matrices, the endothelial and smooth muscle cells were inoculated into microtiter plates (Nunc, Roskilde, Denmark) at a density of 8,000 cells/well. After confluence, the extracellular matrix was isolated as described.

Perfusions. Perfusions with steady flow (22) were carried out with an annular perfusion chamber (23) and a rectangular perfusion chamber (24). The annular perfusion chamber was used for subendothelium and the rectangular perfusion chamber was used for glass cover slips coated with extracellular matrix. Subendothelium was obtained from human umbilical arteries by removing endothelium by exposure to air $(6,22)$, then the vessel was washed three successive times with $10 \mathrm{mM}$ Hepes buffer, $\mathrm{pH} 7.4$, that contained $150 \mathrm{mM}$ $\mathrm{NaCl}$.

Blood from normal human donors was anticoagulated with 1:10 vol $110 \mathrm{mM}$ trisodium citrate. This whole blood was used directly for perfusion experiments. Some perfusions were performed with reconstituted blood. In that case, platelets were first isolated, washed by centrifugation as previously described (10), radiolabeled with ${ }^{111}$ Inoxine (Byk-Mallinckrodt, CIL, Petten, the Netherlands) $(10 \mu \mathrm{Ci} / 1.5$ $\times 10^{8}$ platelets), treated with $10 \mu \mathrm{M}$ aspirin, and washed as previously described (10). Before each perfusion, the perfusate was reconstituted by adding washed red cells to the resuspended platelets in plasma or in a human albumin solution (HAS; KRB containing $0.01 \mathrm{M}$ glucose, 2 $\mathrm{mM} \mathrm{CaCl}_{2}, 19 \mathrm{mM}$ citrate, and $4 \%$ human albumin (Sigma Chemical Co., St. Louis, MO) (hematocrit, 0.4 ; platelet count, $1.14 \times 10^{8} / \mathrm{ml}$ ).

In some experiments, the matrices or subendothelium were preincubated for $1 \mathrm{~h}$ at room temperature with MAbs and diluted 1:100 in PBS. As a control, matrices were incubated with PBS containing control ascites in the same dilution. After the coverslip or subendothelium had been washed extensively, it was inserted into the perfusion chamber and rinsed with $25 \mathrm{ml}$ of $10 \mathrm{mM}$ Hepes-buffered saline, $\mathrm{pH}$ 7.4. The perfusate $(15 \mathrm{ml})$ was prewarmed for $5 \mathrm{~min}$ at $37^{\circ} \mathrm{C}$. In some experiments, the perfusate was preincubated with MAbs (1:100 dilution) during this $5 \mathrm{~min}$. The perfusate was recirculated through the perfusion chamber for 5 min under a nonpulsatile steady flow at wall shear rates of $1,300 \mathrm{~s}^{-1}$ (matrices) or $1,800 \mathrm{~s}^{-1}$ (subendothelium). The coverslip was removed, washed with Hepes saline, and fixed with $0.5 \%$ glutaraldehyde as previously described (24).

Evaluation of platelet adherence. After fixation with glutaraldehyde, the coverslips covered with platelets were stained with May-Grünwald-Giemsa, as previously described (24). Platelet adhesion was expressed as the percentage of the surface covered by platelets. This was evaluated by en face light microscopy at $\times 1,000$. The light microscope was interfaced with an image analyzer (Quantimet 720; Imanco, Royston, U.K.). For every coverslip, 30 fields, each consisting of 500,000 image points $\left(0.028 \mathrm{~mm}^{2}\right)$, were selected at random and evaluated.

Platelet adhesion to subendothelium was determined by counting of "In-radioactivity on the artery segments in a gamma counter.

$M A b s$ and Fab fragments. The preparation and characterization of MAbs directed against the human von Willebrand factor molecule have been described before (17). The properties of MAbs CLB-RAg 35

1. Abbreviations used in this paper: buffer A, $28.5 \mathrm{mM}$ Na-acetate, 28.5 $\mathrm{mM} \mathrm{Na}$-barbital, $116 \mathrm{mM} \mathrm{NaCl}, 0.1 \%$ Tween 20 , and $1 \mathrm{mg} / \mathrm{ml} \mathrm{BSA}$ FPLC, fast protein liquid chromatography; HAS, human albumin solution. and CLB-RAg 201 have been extensively published (5, 14, 17). IgG was purified from ascites as described (17). Fab fragments were prepared according to the method described in Immunochemistry in Practice (25). In short, purified monoclonal IgG was dissolved in $2 \mathrm{ml}$ of $0.1 \mathrm{M} \mathrm{Na}$-acetate and $\sim 8 \mathrm{mg} \mathrm{IgG}$ was digested with $250 \mu \mathrm{g}$ pepsin (Sigma Chemical Co.) for $18 \mathrm{~h}$ at $37^{\circ} \mathrm{C}$. After neutralizing this solution with $300 \mu \mathrm{l}$ of $2 \mathrm{M}$ Tris buffer, $\mathrm{pH} 7.4$, and its centrifugation, the $\mathrm{F}(\mathrm{ab})_{2}$ fragments were isolated with Sephadex G200 gel chromatography. After the $F(a b)_{2}$ fragments were concentrated and dialyzed against Tris-buffered saline (pH 7.4), they were reduced with 1 mM DTT for 1 $\mathrm{h}$ at room temperature. Then iodoacetamide $(10 \mathrm{mM}$ final concentration) was added to the Fab fragments which were then isolated with Sephadex G-200 chromatography. SDS-PAGE showed the absence of $F(a b)_{2}$ fragments in the final preparation. In experiments in which ascites was used instead of purified IgG or Fab fragments, the ascites was diluted 1:100, which corresponds with $\sim 50 \mu \mathrm{g} / \mathrm{ml} \mathrm{IgG} \mathrm{for} \mathrm{CLB-}$

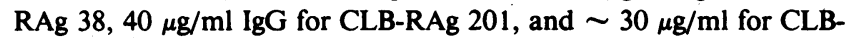
RAg 35 .

Isolation and radiolabeling of von Willebrand factor. von Willebrand factor was isolated from fresh cryoprecipitates by agarose gel filtration on Sepharose CL-4B (Pharmacia, Inc., Uppsala, Sweden) as described previously (26). The von Willebrand factor in the void volume fraction was further purified by passing it over a gelatin Sepharose column, which was equilibrated with $0.005 \mathrm{M}$ Tris- $\mathrm{HCl}$ (pH 7.4). von Willebrand factor was precipitated by dialysis against $1.6 \mathrm{M}$ ammonium sulfate, $\mathrm{pH} 7.0$, at $4^{\circ} \mathrm{C}$ for $18 \mathrm{~h}$, and was stored as ammonium sulfate suspension at $4^{\circ} \mathrm{C}$ until use. The purified von Willebrand preparation contained no fibronectin and less than $2 \%$ fibrinogen.

For radiolabeling, von Willebrand factor was collected from the ammonium sulfate suspension by centrifugation $\left(10,000 \mathrm{~g}, 4^{\circ} \mathrm{C}, 2\right.$ $\mathrm{min}$ ). The pellet was dissolved in $0.05 \mathrm{M}$ sodium-phosphate buffer, $\mathrm{pH}$ 7.0, and dialyzed against this buffer to remove any remaining ammonium sulfate. Radiolabeling with ${ }^{125}$ I was performed with the Iodo-Gen method (27). Nonconvalently bound ${ }^{125} \mathrm{I}$ was removed by dialysis at $4^{\circ} \mathrm{C}$ against $0.05 \mathrm{M}$ Tris- $\mathrm{HCl}, 0.1 \mathrm{M} \mathrm{NaCl}, \mathrm{pH}$ 7.4. Incorporation of radiolabel was $10 \%$ and preparations with a specific activity of 55 $\mu \mathrm{Ci} / \mathrm{mg}$ were obtained. Free ${ }^{125} \mathrm{I}$ was $<2 \%$. The multimeric structure of von Willebrand factor was unaltered by the radiolabeling.

Binding of von Willebrand factor to purified proteins. Binding of von Willebrand factor to collagen or fibronectin adsorbed to polystyrene microtiter wells (Costar, Data Packaging Corp., Cambridge, MA) was assayed according to Mumby et al. (28). In short, wells of 96-well microtiter plates were coated overnight with $100 \mu \mathrm{l}$ collagen $(5 \mu \mathrm{g} / \mathrm{ml})$ in $50 \mathrm{mM}$ acetic acid. The microtiter plate was rinsed three times with buffer A (28.5 mM Na-acetate, $28.5 \mathrm{mM}$ Na-barbital, $116 \mathrm{mM} \mathrm{NaCl}$, $0.1 \%$ Tween 20 , and $1 \mathrm{mg} / \mathrm{ml} \mathrm{BSA}, \mathrm{pH} 7.35) .100 \mu \mathrm{l}$ plasma or $100 \mu \mathrm{l}$ purified von Willebrand factor $(5 \mu \mathrm{g} / \mathrm{ml})$ was added to buffer $A$ for $1 \mathrm{~h}$ at room temperature. The plate was rinsed as before, and $100 \mu \mathrm{l}$ of a 1:2,000 diluted peroxidase-conjugated rabbit anti-human von Willebrand factor (DAKO, Copenhagen, Denmark) was added for $1 \mathrm{~h}$ at room temperature. The plate was rinsed as before and incubated for 20 min at room temperature with $8 \mathrm{mg} / \mathrm{ml} o$-phenylenediamine and $0.015 \% \mathrm{H}_{2} \mathrm{O}_{2}$ in $50 \mathrm{mM}$ citric acid, $100 \mathrm{mM} \mathrm{Na}_{2} \mathrm{HPO}_{4}$, pH 5.0. The reaction was stopped with $4 \mathrm{M} \mathrm{H}_{2} \mathrm{SO}_{4}$, and absorbance was determined at $450 \mathrm{~nm}$ with a titertek Multiscan microtiter plate autoreactor. (Flow Laboratories, Inc., Rockville, MD).

Collagen types I and III were purified as described (28). Collagen types IV and V were a generous gift of Dr. Houdijk (University Hospital Utrecht, the Netherlands); collagen type VI was a generous gift of Drs. Dziadek and Timpl, (Max Planck Institute, Munich, FRD).

Fibronectin was isolated from normal human plasma by affinity chromatography on gelatin Sepharose, as published (29).

Binding of von Willebrand factor to extracellular matrices. Binding of ${ }^{125}$ I-von Willebrand factor to extracellular matrices of cells cultured in 96-well microtiter wells was assayed as follows: ${ }^{125} \mathrm{I}$-von Willebrand factor was diluted to $2 \mu \mathrm{g} / \mathrm{ml}$ in buffer $\mathrm{A}$, and $50 \mu \mathrm{l}$ of this solution was incubated for $2 \mathrm{~h}$ at room temperature in the presence or absence of MAbs in the microtiter wells. After washing the wells three times with 
$200 \mu \mathrm{l}$ buffer A, $50 \mu \mathrm{l}$ of a dissolving buffer (10 mM EDTA, 1\% SDS, and $1 \%$ Triton $\mathrm{X}-100$ ) was added, and the matrices were scraped off the bottom of the wells, transferred to plastic tubes, and counted in a gamma counter. Glutaraldehyde-fixed endothelial or smooth muscle cells or wells without cells were used as blanks. The binding to the blanks were all less than $10 \%$ of the binding to the matrices.

The binding of ${ }^{125} \mathrm{I}$-von Willebrand factor to subendothelium was assayed in the perfusion system (14). Subendothelium was exposed to 1 $\mu \mathrm{g} / \mathrm{ml}{ }^{125} \mathrm{I}$-von Willebrand factor $(25 \mathrm{nCi} / \mathrm{ml})$ in $4 \%$ HAS for $5 \mathrm{~min}$ at a shear rate of $1,800 \mathrm{~s}^{-1}$. The amount of von Willebrand factor that was bound to the surface was calculated from the specific radioactivity and the radioactivity on the surface after perfusion. Radioactivity was measured in a gamma counter.

Binding of von Willebrand factor to platelets. Human blood was collected into 1:10 vol of $110 \mathrm{mM}$ trisodium citrate, and platelet-rich plasma was obtained by centrifugation $\left(20^{\circ} \mathrm{C}, 10 \mathrm{~min}, 150 \mathrm{~g}\right)$. Platelets were washed three times by centrifugation as previously described (6). After the platelets were washed, they were resuspended in Tyrode buffer ( $140 \mathrm{mM} \mathrm{NaCl}, 2.7 \mathrm{mM} \mathrm{KCl}, 0.42 \mathrm{mM} \mathrm{NaH}_{2} \mathrm{PO}_{4}$, and $12 \mathrm{mM}$ $\mathrm{NaHCO}_{3}, \mathrm{pH} 7.4$ ), which contained $1 \mathrm{mM} \mathrm{CaCl}, 5 \mathrm{mM}$ glucose, and $3.5 \mathrm{mg} / \mathrm{ml}$ of human albumin. ${ }^{125} \mathrm{I}$-von Willebrand factor was diluted to $4 \mu \mathrm{g} / \mathrm{ml}$ in this Tyrode buffer. $0.25 \mathrm{ml}$ of this solution was mixed with $0.25 \mathrm{ml}$ platelet suspension, which contained $1.5 \times 10^{8}$ platelets. Thrombin (Sigma Chemical Co.) was added to a final concentration of $0.5 \mathrm{U} / \mathrm{ml}$. $0.8 \mathrm{mg}$ ristocetin was first mixed with the ${ }^{125} \mathrm{I}$-von Willebrand solution. After incubation for $30 \mathrm{~min}$ at room temperature, the mixtures were layered on top of $1 \mathrm{ml} 20 \%$ sucrose solution and then centrifuged $(1 \mathrm{~min}, 10,000 \mathrm{~g}$ ). The pellet was counted in a gamma counter.

To determine the effect of the MAbs to von Willebrand factor, these antibodies were included in the incubation mixture at a final dilution of $1: 100$ (ascites).

Tryptic digestion of von Willebrand factor and separation of the fragments. $45 \mathrm{mg}$ von Willebrand factor in $20 \mathrm{ml}$ of $0.05 \mathrm{M}$ Tris- $\mathrm{HCl}$, $0.1 \mathrm{M} \mathrm{NaCl}, \mathrm{pH} \mathrm{7.4}$, was incubated for $24 \mathrm{~h}$ at $37^{\circ} \mathrm{C}$ with $\mathrm{L}$ (tosylamido 2-phenyl)ethylchloromethylketone-treated trypsin (Worthington, Freehold, NJ) (enzyme to substrate ratio 1:2.2 [mol/mol]). The incubation was finished with a mixture of inhibitors $(12.5 \mathrm{mM}$ benzamidine, $12.5 \mathrm{mM} \epsilon$-aminocaproic acid, and soy bean trypsin inhibitor, twofold molar excess).

The digest was fractionated using fast protein liquid chromatography (FPLC) Mono-Q ionexchange chromatography (Pharmacia, Inc.). The column was equilibrated with $20 \mathrm{mM}$ Tris- $\mathrm{HCl}, \mathrm{pH} \mathrm{7.6,} \mathrm{and} 0.1 \%$ Tween 20; under these conditions all peptides bound to the column. The tryptic fragments were eluted with a linear gradient of $\mathrm{NaCl}(0-0.5$ $M)$, and fractions were collected. The absorbance at $280 \mathrm{nM}$ of the eluate was recorded continuously with a spectrophotometer (Uvicord S; LKB Instruments, Bromma, Sweden). Peak fractions were pooled as indicated and applied to gel electrophoresis and immunoblotting.

SDS-slab gel electrophoresis was performed on 3-30\% PAGE (280 $\times 140 \times 0.75 \mathrm{~mm}$ ) according to Laemmli (30). The gels were run at $200 \mathrm{~V}$ (constant voltage) for $20 \mathrm{~h}$. Some gels were stained with Coomassie Brilliant Blue R-250 and dried. From other gels, the proteins were transferred electrophoretically to nitrocellulose filters (Schleider and Schultz, Darsel, FRG) essentially as described by Towbin et al. (31). The nitrocellulose paper was washed with a buffer containing 10

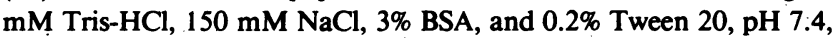
and was then incubated overnight with the different MAbs diluted 1:1,000 in the same buffer. After the filters were washed, they were incubated with peroxidase-labeled rabbit anti-mouse IgG (Nordic Immunology, Tilburg, The Netherlands) 1:1,000 dilution in washing buffer. The proteins were visualized with diamino-benzidine-tetrahydrochloride $(0.5 \mathrm{~g} /$ liter in $50 \mathrm{~mm}$ Tris- $\mathrm{HCl}$ buffer, $\mathrm{pH} \mathrm{7.6,} \mathrm{containing}$ $0.006 \% \mathrm{H}_{2} \mathrm{O}_{2}$ ).

\section{Results}

Binding of von Willebrand factor to matrices of endothelial cells and smooth muscle cells. In a previous study (14), we have found an MAb against von Willebrand factor (CLB-RAg 201) that inhibits the binding of von Willebrand factor to purified fibrillar collagen types I and III. This MAb did not inhibit the binding of von Willebrand to the subendothelium (reference 14 and Table I).

We now have screened a panel of MAbs for their ability to inhibit the binding of von Willebrand factor to extracellular matrices of cultured endothelial cells and smooth muscle cells. As shown in Table I, CLB-RAg 201 has no significant influence on the binding of von Willebrand factor to the matrices. However, another MAb, CLB-RAg 38, inhibited the binding of von Willebrand factor to both types of matrix to the same extent as an excess amount of unlabeled von Willebrand factor did (Table I). Using purified IgG, $4.8 \mu \mathrm{g} / \mathrm{ml} \mathrm{CLB-RAg} 38 \mathrm{com}$ pletely inhibits the binding of ${ }^{125} \mathrm{I}$-von Willebrand factor to endothelial cell matrices, while up to $200 \mu \mathrm{g} / \mathrm{ml}$ CLB-RAg 201 had no significant effect on it. CLB-RAg 35, an MAb that inhibits the interaction between von Willebrand factor and platelets, had no influence on the binding of von Willebrand factor to the matrices.

The effect of CLB-RAg 201 and CLB-RAg 38 on the binding of von Willebrand factor to endothelial cell matrices was also tested in the perfusion system. Perfusions were performed with $2 \mu \mathrm{g} / \mathrm{ml}^{125} \mathrm{I}$-von Willebrand factor added to a $4 \%$ HAS. A mean value of $11.4 \mathrm{ng}{ }^{125} \mathrm{I}$-von Willebrand factor bound $/ \mathrm{cm}^{2}$ of the coverslips. In the presence of CLB-RAg 38, $6.0 \mathrm{ng}{ }^{125} \mathrm{I}-$ von Willebrand factor was bound $/ \mathrm{cm}^{2}$; no inhibition was found in the presence of CLB-RAg 201.

In another series of experiments, the binding of ${ }^{125} \mathrm{I}$-von Willebrand factor to the subendothelium of human umbilical arteries was studied (Table I). A rapid binding of von Willebrand factor was found. This binding however, could not be inhibited by a 20 -fold excess of unlabeled von Willebrand factor. This indicates that the binding of von Willebrand factor to the denuded arteries in this concentration range is not saturable (see also reference 6). This may be the reason that no inhibition occurred with any of the MAbs.

Table I. Binding of ${ }^{125}$ I-von Willebrand Factor to Matrices of Cultured Cells and Subendothelium

\begin{tabular}{lccc}
\hline & \multicolumn{3}{c}{${ }^{125} \mathrm{I}-\mathrm{vWF}$ bound $\left(\mathrm{ng} / \mathrm{cm}^{2}\right)$} \\
\cline { 2 - 4 } & $\begin{array}{c}\text { EC } \\
\text { matrix }\end{array}$ & $\begin{array}{c}\text { SMC } \\
\text { matrix }\end{array}$ & Subendothelium \\
\hline Control & $7.7 \pm 2.8$ & $6.5 \pm 2.2$ & $18.5 \pm 2.9$ \\
Control + excess vWF & $2.3 \pm 0.6$ & 0 & $19.3 \pm 0.2$ \\
Control + CLB-RAg 35 & $7.3 \pm 1.4$ & $6.6 \pm 1.8$ & $15.5 \pm 0.9$ \\
Control + CLB-RAg 201 & $5.9 \pm 0.3$ & $6.1 \pm 0.6$ & $17.5 \pm 2.9$ \\
Control + CLB-RAg 38 & $2.3 \pm 0.6$ & $1.1 \pm 1.1$ & $14.9 \pm 3.7$ \\
\hline
\end{tabular}

Endothelial cells (EC) or smooth muscle cells (SMC) were cultured in microtiter wells. After isolation, the matrices were incubated for 2 $\mathrm{h}$ with $2 \mu \mathrm{g} / \mathrm{ml}^{125} \mathrm{I}$-von Willebrand factor (vWF). Excess of unlabeled von Willebrand factor was $20 \mu \mathrm{g} / \mathrm{ml}$. After washing the matrices three times, they were scraped off and counted. Results are expressed as mean $\pm \mathrm{SD}(n=6)$. Subendothelium was perfused for 5 $\min$ with $1 \mu \mathrm{g} / \mathrm{ml}{ }^{125} \mathrm{I}$-von Willebrand factor at a shear rate of 1,800 $\mathrm{s}^{-1}$. After washing the subendothelium, the radioactivity bound to the subendothelium was counted. Results are expressed as mean \pm SD $(n=3)$. Excess von Willebrand factor was $20 \mu \mathrm{g} / \mathrm{ml}$. 
Table II. Binding of von Willebrand Factor to Purified Collagens and Fibronectin

\begin{tabular}{|c|c|c|c|c|c|c|}
\hline & Plasma & $\begin{array}{c}\text { Plasma } \\
+ \text { CLB-RAg } 35\end{array}$ & $\begin{array}{c}\text { Plasma } \\
+ \text { CLB-RAg } 38\end{array}$ & $\begin{array}{c}\text { Plasma } \\
+ \text { + Fab CLB-Rag } 38\end{array}$ & $\begin{array}{c}\text { Plasma } \\
+ \text { CLB-RAg } 201\end{array}$ & $\begin{array}{c}\text { Plasma } \\
+ \text { + Fab CLB-RAg } 201\end{array}$ \\
\hline \multicolumn{7}{|l|}{ Collagen type I } \\
\hline Fibrillar & $1,916 \pm 72$ & $1,669 \pm 129$ & $1,593 \pm 136$ & $1,657 \pm 41$ & $43 \pm 7$ & $40 \pm 9$ \\
\hline Monomeric & $52 \pm 9$ & $60 \pm 8$ & $42 \pm 12$ & - & $28 \pm 5$ & - \\
\hline \multicolumn{7}{|l|}{ Collagen type III } \\
\hline Fibrillar & $466 \pm 98$ & - & $421 \pm 56$ & - & $42 \pm 6$ & - \\
\hline Monomeric & $570 \pm 77$ & - & $478 \pm 65$ & - & $35 \pm 9$ & 一 \\
\hline Collagen type IV & $51 \pm 10$ & - & $59 \pm 17$ & - & $63 \pm 13$ & - \\
\hline Collagen type $\mathrm{V}$ & $65 \pm 17$ & $69 \pm 28$ & $61 \pm 10$ & - & $86 \pm 25$ & - \\
\hline Collagen type VI & $55 \pm 9$ & - & $87 \pm 10$ & - & $78 \pm 24$ & - \\
\hline Fibronectin & $103 \pm 16$ & $100 \pm 9$ & $79 \pm 10$ & - & $95 \pm 31$ & - \\
\hline
\end{tabular}

Purified collagens $(1 \mu \mathrm{g} / \mathrm{ml})$ or $1 \mu \mathrm{g} / \mathrm{ml}$ fibronectin were coated overnight to microtiter wells. The wells were then incubated for $1 \mathrm{~h}$ with plasma. After washing the wells three times, the amount of von Willebrand factor bound to the collagens was determined by incubating the wells for $1 \mathrm{~h}$ with a peroxidase-conjugated polyclonal antibody against von Willebrand factor, and the peroxidase was subsequently assayed with $o$-phenylenediamine and $\mathrm{H}_{2} \mathrm{O}_{2}$. The results are expressed as absorbance at $450 \mathrm{~nm}$ (mean $\pm \mathrm{SD}, n=4$ ).

Binding of von Willebrand factor to purified collagens. The inhibition of binding of von Willebrand factor by CLB-RAg 38 was studied in more detail (Table II). Various types of collagen and fibronectin were coated onto microtiter wells and then incubated with plasma. von Willebrand factor bound strongly to fibrillar collagen type I and to fibrillar and monomeric collagen type III. This binding was inhibited by CLB-RAg 201 but not by CLB-RAg 38. When using purified IgG, $1 \mu \mathrm{g} / \mathrm{ml} \mathrm{CLB-}$ RAg 201 completely inhibits the binding while $480 \mu \mathrm{g} / \mathrm{ml}$ CLB-RAg 38 has no effect at all on the binding of von Willebrand factor to collagen type III. von Willebrand factor did not bind to monomeric collagen types I, IV, V, VI, or to fibronectin. This absence of interaction was not due to the lack of binding of the latter collagens and fibronectin to plastic since their presence was readily demonstrated by an ELISA using the appropriate specific antisera (data not shown). When purified von Willebrand factor was used instead of plasma, comparable results were obtained, except that purified von Willebrand factor also bound to collagen type $\mathrm{V}$ (not shown). This binding could not be inhibited by both CLB-RAg 201 and CLB-RAg 38. When Fab fragments obtained from CLB-RAg 201 and CLB-RAg 38 were used to study the inhibition of von Willebrand factor to fibrillar collagen type $I$, the same results were obtained as with the MAbs themselves.

Platelet adhesion to extracellular matrices. In order to investigate the role of the different domains on von Willebrand factor in the interaction of platelets with the extracellular matrices of endothelial cells and smooth muscle cells, and with subendothelium, perfusions were performed with whole blood preincubated with the different MAbs (Table III). Platelet adhesion to the matrix of endothelial cells and to subendothelium was completely inhibited by CLB-RAg 35. Previously, (17) it has been shown that this antibody completely inhibited both the binding of von Willebrand factor to platelets in the presence of ristocetin and the adhesion of platelets to subendothelium. Preincubation of plasma with $48 \mu \mathrm{g} / \mathrm{ml} \mathrm{CLB-RAg}$ 38 or with $40 \mu \mathrm{g} / \mathrm{ml}$ CLB-RAg 201 partly inhibited the adhesion of platelets to endothelial cell matrices and subendothelium. The adhesion of platelets to smooth muscle cell matrices was inhibited for $\sim 75 \%$ by CLB-RAg 38 and CLB-RAg 35 , while CLB-RAg 201 inhibited platelet adhesion to these matrices for $\sim 45 \%$.

The adhesion of platelets to subendothelial structures at high wall shear rates depends on both plasma von Willebrand factor and von Willebrand factor already present in the subendothelium. To discriminate between the contribution of plasma and matrix-bound von Willebrand factor to the platelet adhesion, perfusions were carried out with endothelial cell matrices or with subendothelium pretreated with CLB-RAg 35 to block the von Willebrand factor present in the matrix. These matrices were then perfused with whole blood in the

Table III. Adhesion of Platelets to Extracellular Matrices and Subendothelium, and the Inhibition by MAbs

\begin{tabular}{lccc}
\hline & \multicolumn{4}{c}{ Platelet adherence (\% of controls) } \\
\cline { 2 - 4 } \multicolumn{1}{c}{ Perfusate } & $\begin{array}{c}\text { EC matrix } \\
(\text { mean } \pm \text { SD) }\end{array}$ & SMC matrix & Subendothelium \\
\hline WB + control ascites & 100 & 100 & 100 \\
WB + CLB-RAg 35 & $5 \pm 2(n=11)$ & $24(n=2)$ & $6 \pm 2(n=7)$ \\
WB + CLB-RAg 201 & $59 \pm 3(n=10)$ & $55(n=2)$ & $59 \pm 12(n=8)$ \\
WB + CLB-RAg 38 & $57 \pm 7(n=4)$ & $28(n=2)$ & $55 \pm 9(n=5)$ \\
& & & \\
\hline
\end{tabular}

Endothelial cell (EC) and smooth muscle cell (SMC) matrices were perfused with whole blood for $5 \mathrm{~min}$ at a shear rate of $1,300 \mathrm{~s}^{-1}$. Subendothelium was perfused for $5 \mathrm{~min}$ at a shear rate of $1,800 \mathrm{~s}^{-1}$ with a perfusate that consisted of washed red blood cells ( $40 \%$ hematocrit), normal citrated plasma, and ${ }^{111}$ In-labeled blood platelets (final concentration $205 \times 10^{3} / \mu \mathrm{l}$ ). MAbs were added to the plasma $5 \mathrm{~min}$ before the perfusion. After perfusion the matrices were fixed and stained, and the surface coverage by platelets was determined by morphometric evaluation. The number of platelets adhering to subendothelium was calculated from the specific radioactivity and the radioactivity on the surface after perfusion. Results are expressed as $\%$ of adherence to matrices or to subendothelium preincubated with control ascites (mean \pm SD). WB, whole blood. 
presence or absence of MAbs (Table IV). CLB-RAg 35 and CLB-RAg 38 almost completely blocked the residual platelet adhesion to the endothelial matrix while CLB-RAg 201 showed only a small inhibition. Comparable results were found with Fab fragments obtained from CLB-RAg 38 and CLB-RAg 201. The adhesion to subendothelium was completely inhibited with CLB-RAg 35. Both CLB-RAg 201 and CLB-RAg 38 gave partial inhibition. When Fab fragments of both monoclonals were combined no additional inhibition was seen.

To further examine the contradictory results with CLBRAg 201 (no inhibition of the binding of ${ }^{125}$ I-von Willebrand factor to the matrix but partial inhibition of platelet adhesion), double perfusion studies were performed (Table V). First perfusions were carried out with plasma alone or with plasma with added MAbs. Then a second perfusion was carried out with ${ }^{111}$ In-labeled platelets $(190,000 / \mu \mathrm{l})$ and red blood cells (hematocrit, $40 \%$ ) resuspended in HAS, with or without MAbs. When subendothelium was perfused first with plasma, to which CLB-RAg 38 or CLB-RAg 201 was added, and subsequently with In-labeled platelets, an inhibition comparable with the results shown in Table III occurred. However, when the subendothelium was first perfused with plasma (containing von Willebrand factor), and then with platelets and MAbs (in the absence of von Willebrand factor), CLB-RAg 201 still inhibited the platelet adhesion while CLB-RAg 38 had no inhibitory effect anymore. These results indicate that CLB-RAg 201 inhibited the functional activity of the von Willebrand factor

Table IV. Adhesion of Platelets to Endothelial Cell Matrices and Subendothelium Pretreated with CLB-RAg 35

\begin{tabular}{lcc}
\hline & \multicolumn{2}{c}{ Platelet adherence } \\
\cline { 2 - 3 } \multicolumn{1}{c}{ Perfusate } & $\begin{array}{c}\text { EC matrix } \\
\text { (\% surface coverage) }\end{array}$ & $\begin{array}{c}\text { Subendothelium } \\
\text { (platelets } \times 10^{5} / \mathrm{cm} \text { ) }\end{array}$ \\
\hline WB & $16.2 \pm 2.7$ & $26.0 \pm 1.0$ \\
WB + CLB-RAg 38 & $2.5 \pm 1.1$ & $10.4 \pm 3.0$ \\
WB + CLB-RAg 201 & $11.3 \pm 2.1$ & $8.4 \pm 2.7$ \\
WB + CLB-RAg 35 & $0.6 \pm 0.3$ & $4.8 \pm 2.2$ \\
WB + Fab CLB-RAg 38 & $2.5 \pm 1.1$ & - \\
WB + Fab CLB-RAg 201 & $12.2 \pm 0.5$ & - \\
\hline
\end{tabular}

Endothelial cell (EC) matrices or subendothelium were preincubated with CLB-RAg 35 (1:100 dilution, half an hour at room temperature) to block the von Willebrand factor present in the matrix. After washing the endothelial cell matrices, they were perfused for $5 \mathrm{~min}$ with whole blood (WB) with or without MAbs at a shear rate of $1,300 \mathrm{~s}^{-1}$. The subendothelium was perfused for $5 \mathrm{~min}$ with a perfusate that consisted of washed red blood cells ( $40 \%$ hematocrit), normal citrated plasma, and " In-labeled blood platelets (final concentration $\left.2 \times 10^{5} / \mu \mathrm{l}\right)$. The number of blood platelets adhering to the subendothelium was calculated from the specific radioactivity and the radioactivity on the surface after perfusion. On a nontreated subendothelium, the number of blood platelets adhering was $67.5 \pm 3.1$ $\times 10^{5}$. Platelet adherence to matrices was expressed as percentage of matrix covered with platelets. On matrices, pretreated with a control ascites, platelet coverage was $43.1 \pm 2.2 \%$. On matrices preincubated with CLB-RAg 35, addition of control ascites to the perfusate had no effect on platelet adhesion. Results are expressed as mean $\pm \operatorname{SD}(n=4)$.
Table V. Platelet Adhesion to Subendothelium in Double Perfusion Experiments

\begin{tabular}{ccc}
\hline $\begin{array}{c}\text { First perfusion } \\
\text { Normal plasma addition }\end{array}$ & $\begin{array}{c}\text { Second perfusion } \\
\text { Platelets in HAS addition }\end{array}$ & $\begin{array}{c}\text { Adhesion } \\
\text { Number of platelets } \\
\times 10^{-5} / \mathrm{cm}^{2}\end{array}$ \\
\hline- & - & 31.1 \\
CLB-RAg 38 & - & 17.9 \\
CLB-RAg 201 & - & 20.1 \\
- & CLB-RAg 38 & 35.1 \\
- & CLB-RAg 201 & 20.3 \\
- & CLB-RAg 35 & 3.4 \\
\hline
\end{tabular}

Subendothelium was first perfused for $5 \mathrm{~min}$ with normal plasma with or without MAbs as indicated. After washing the subendothelium with Hepes buffer, it was perfused a second time with ${ }^{111}$ Inlabeled platelets $/ 190,000(\mu \mathrm{l})$ and with red blood cells (hematocrit 40) resuspended in HAS, with or without antibodies. The results are the mean of two different experiments and are expressed as the number of platelets $\times 10^{-5} / \mathrm{cm}^{2}$. When the first perfusion was performed with HAS alone and the second with platelets and red cells resuspended in HAS, $22.1 \times 10^{5}$ platelets $/ \mathrm{cm}^{2}$ were found, which indicates that platelet adhesion depended on vessel-wall von Willebrand factor.

already bound to the subendothelium, whereas CLB-RAg 38 worked by interfering with the binding of von Willebrand factor to the matrix.

Thrombin or ristocetin-induced binding of ${ }^{125} I$-von Willebrand factor to platelets. Both thrombin and ristocetin induced specific and saturable binding of von Willebrand factor to washed platelets, as was shown previously by others (32-34). The binding of ${ }^{125} \mathrm{I}$-von Willebrand factor to platelets was investigated in the presence of the MAbs CLB-RAg 35, CLBRAg 38, and CLB-RAg 201. CLB-RAg 35 inhibited, as was previously reported (19), the binding of von Willebrand factor to platelets in the presence of ristocetin, but not in the presence of thrombin. CLB-RAg 38 and CLB-RAg 201 had no effect on the binding of von Willebrand factor to platelets in the presence of either thrombin or ristocetin.

Tryptic digestion of von Willebrand factor and purification of fragments. The results described above suggest that CLBRAg 201 and CLB-RAg 38 recognize different epitopes on von Willebrand factor. To identify the domains containing the epitopes, von Willebrand factor was digested with trypsin for $24 \mathrm{~h}$. The various von Willebrand fragments were then isolated using FPLC Mono Q-chromatography. This resulted in the separation of several fragments of the von Willebrand factor molecule (Fig. 1). In order to characterize the domains recognized by the MAbs present on the fragments, the peak fractions were pooled, applied to gel electrophoresis, and immunoblotted. Although the main fragment present in pool 2 was a 20-kD peptide shown with Coomassie staining, after blotting CLB-RAg 201, it recognized a fragment with a molecular weight of 48,000 in this pool. Another fragment with a molecular weight of 82,000 present in pool 4 was recognized by CLB-RAg 38. This fragment was also recognized by CLB-RAg 41. This MAb has previously been used for the recognition of von Willebrand factor-specific cDNA in an endothelial cell cDNA library. Its epitope appeared to reside on the $37,000 \mathrm{D}$ carboxy-terminal fragment of the molecule (35). 


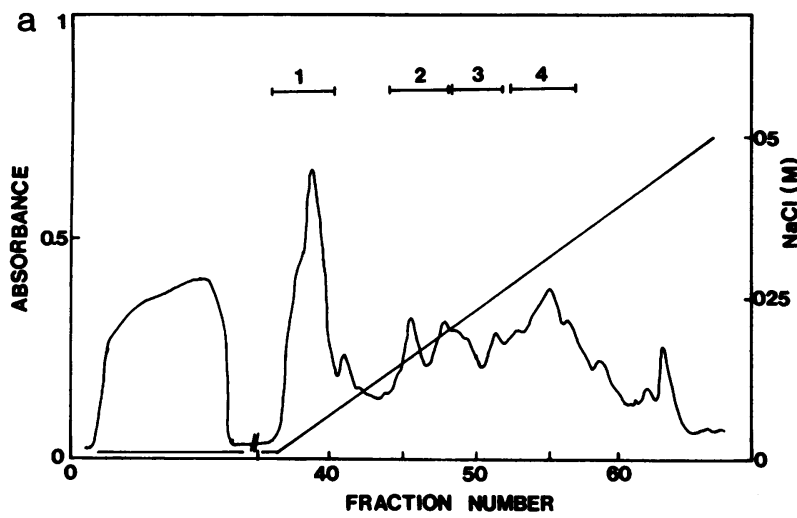
of von Willebrand factor. $45 \mathrm{mg}$ von Willebrand factor was digested for $24 \mathrm{~h}$ with L(tosylamido 2-phenyl)ethylchloromethylketone-FPLC treated trypsin. The digest was applied to FPLC Mono Q-ionexchange chromatography; the tryptic fragments were eluted with a linear gradient of $\mathrm{NaCl}(0-0.5 \mathrm{M})$, and fractions were collected $(a)$. Based on the absorbance at $280 \mathrm{nM}$, the fractions were pooled as indicated and applied to a 3-30\% PAGE. After electrophoresis, gels were stained with Coomassie Brilliant Blue R-250 $(C B)$ or the proteins were electrophoretically transferred to nitrocellulose filter. After washing the filters, they were incubated with 1:100 dilution of CLB-RAg $201(b)$ or CLB-RAg $38(c)$. The MAbs were detected by incubation with peroxidase-labeled rabbit anti-mouse, followed by incubation with benzidine-tetrahydrochloride $(0.5 \mathrm{~g} /$ liter in $50 \mathrm{nM}$ Tris$\mathrm{HCl}$ buffer, $\mathrm{pH} 7.6$, containing $0.006 \% \mathrm{H}_{2} \mathrm{O}_{2}$ ).

\section{Discussion}

von Willebrand factor mediates the binding of platelets to subendothelium after vascular injury. von Willebrand factor is present in the subendothelium (8), deposited by the endothelial cells, but for optimal platelet adhesion, plasma von Willebrand factor is also necessary. Several groups of investigators have demonstrated that von Willebrand factor binds strongly to collagen types I and III, and therefore collagen has been considered to be the binding site of von Willebrand factor in the damaged vessel wall (9-14).

Recently, Hormia et al. (16) and Wagner et al. (15) presented indirect evidence that not collagen but another matrix protein may be the binding site of von Willebrand factor in the extracellular matrix of cultured cells. Their results were mainly based on immunofluorescence studies, and both groups suggested an important role for fibronectin. Their findings were in agreement with the findings of Rand et al. (8), who reported that collagenase treatment did not affect the subendothelial localization of von Willebrand factor in human vessels. Our own group has described an MAb, CLB-RAg 201, which is directed against the domain on the von Willebrand factor molecule responsible for the binding of von Willebrand factor to collagen (14). This MAb partly inhibited the binding of platelets to subendothelium, but did not affect the binding of von
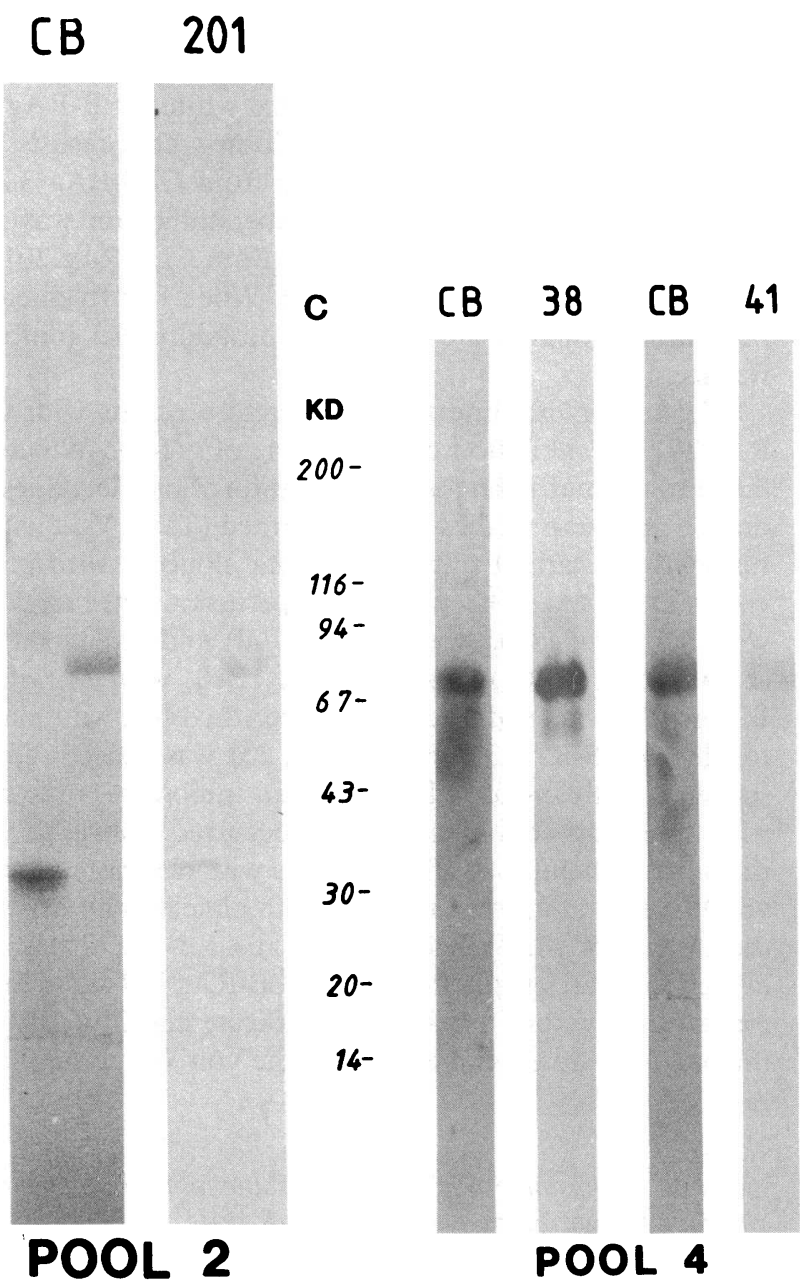

Willebrand factor to subendothelium. We explained this discrepancy by assuming that relatively few von Willebrand factor molecules were needed to bind to sites in the subendothelium that were relevant for the support of platelet adhesion. Most other molecules were thought to bind to irrelevant, aspecific sites in the subendothelium.

To investigate this discrepancy more carefully, we have studied the binding of von Willebrand factor to subendothelial structures in relation to platelet adhesion with a panel of MAbs directed against von Willebrand factor. For these studies, we used the isolated extracellular matrices of cultured human endothelial cells and smooth muscle cells in order to avoid aspecific binding of von Willebrand factor to the spongy surface of denuded arteries. The results found with the cellular matrices were then later corroborated in studies with the subendothelium of denuded umbilical arteries. Table VI summarizes the effects of different MAbs on the binding of von Willebrand factor and on the adhesion of platelets to subendothelial structures. CLB-RAg 38 inhibited the binding of von Willebrand factor to extracellular matrices completely and had no effect on its binding to purified collagens. In contrast, CLB-RAg 201 inhibited the binding of von Willebrand factor to purified collagens but not to extracellular matrices. Both CLB-RAg 38 and partly CLB-RAg 201 inhibited the binding of platelets to these surfaces at high shear rate. When von Willebrand factor, al- 
ready present on the surfaces, was blocked by another MAb, platelet adhesion was almost completely inhibited by CLBRAg 38. In this latter situation, platelet adhesion is completely dependent on plasma von Willebrand factor. CLB-RAg 201 produced a partial inhibition of platelet adhesion on cellular matrices. However, as was shown in Table V, CLB-RAg 201 also partly inhibited the adhesion of platelets that depend on the von Willebrand factor already present in the subendothelium. This indicates that CLB-RAg 201 interferes directly with the platelet-von Willebrand factor interaction. The domain on the von Willebrand factor molecule recognized by CLB-RAg 38 was located in a part of the molecule other than the collagen-binding domain. These results strongly indicate that collagen is not the binding site for von Willebrand factor in the extracellular matrix of cultured vessel-wall cells.

These data do not necessarily exclude the possibility that collagen could also be an extra binding site of von Willebrand factor in the subendothelium of denuded arteries. Due to the unsaturability of von Willebrand factor's binding to subendothelium, it was impossible to study which epitopes on the von Willebrand factor were involved in this binding. CLBRAg 38 showed an almost complete inhibition of platelet adhesion when this adhesion depended on plasma von Willebrand factor only (Tables IV and V). No inhibition could be found when von Willebrand factor was already bound to the subendothelium before the antibodies were added (Table V). CLB-RAg 201, the MAb directed to the epitope present on the von Willebrand factor molecule involved in the interaction

Table VI. Summary of the Effects of the MAbs on Platelets Adhesion and Binding of Von Willebrand Factor

\begin{tabular}{|c|c|c|c|}
\hline Inhibition of: & CLB-RAg 35 & CLB-RAg 38 & CLB-RAg 201 \\
\hline $\begin{array}{l}\text { Platelet } \\
\text { adhesion } \\
\text { (whole blood) }\end{array}$ & ++ & $+1-$ & $+1-$ \\
\hline $\begin{array}{l}\text { Platelet } \\
\text { adhesion } \\
\text { depending } \\
\text { only on } \\
\text { plasma vWF }\end{array}$ & ++ & ++ & $\begin{array}{l}+/-(++ \text { for } \\
\text { subendothelium })\end{array}$ \\
\hline $\begin{array}{l}\text { Binding of vWF } \\
\text { to subcellular } \\
\text { structures }\end{array}$ & - & ++ & - \\
\hline $\begin{array}{l}\text { Binding of vWF } \\
\text { to collagen } \\
\text { types I and III }\end{array}$ & - & - & ++ \\
\hline $\begin{array}{l}\text { Binding of vWF } \\
\text { to platelets } \\
\text { (ristocetin } \\
\text { induced) }\end{array}$ & ++ & - & - \\
\hline $\begin{array}{l}\text { Binding of vWF } \\
\text { to platelets } \\
\text { (thrombin } \\
\text { induced) }\end{array}$ & - & - & - \\
\hline
\end{tabular}

For details see the text. ++ , complete inhibition; $+/-$, partial inhibition; -, no inhibition, vWF, von Willebrand factor. with collagen types I and III, partly inhibits platelet adhesion. When von Willebrand factor was first bound to the subendothelium, and then platelets were perfused in the presence of CLB-RAg 201, the adhesion was inhibited to the same extent as when the antibody was added together with the von Willebrand factor (Table V). This indicates that the extent to which CLB-RAg 201 inhibits the adhesion depends on both plasma and vessel-wall von Willebrand factor. This inhibition may be due to steric hindrance of the IgG when it is bound to the molecule at a site that is not directly involved in platelet adhesion. CLB-RAg 201 did not compete with CLB-RAg 35 or CLB-RAg 38 in a competitive RIA (not shown), which indicates that the epitopes were not closely related. Tryptic digestion followed by separation of the fragments or by immunoprecipitation (reference 14 and Fig. 1) showed that the epitopes for CLB-RAg 201, CLB-RAg 38, and CLB-RAg 35 were located on totally different fragments. It is possible that, although the collagen binding epitope is not directly involved in the binding of von Willebrand factor to the subendothelium, it participates in platelet adhesion by serving as an additional, or second, interaction site of von Willebrand factor with the vessel wall, which results in a conformational change of the von Willebrand factor molecule. The binding of von Willebrand factor to subendothelium has been postulated to be accompanied by a change in conformation, which allows the interaction with platelets, because von Willebrand factor in plasma does not bind to circulating platelets. We have to emphasize that we have studied von Willebrand factor binding and platelet interaction with subendothelium. In bleeding time skin wounds, perivascular collagen fibers become exposed and von Willebrand factor might mediate platelet adhesion to these fibers. There may be a difference between von Willebrand binding in a thrombotic situation (minimal damage, binding to subendothelium) and in a hemostatic situation (breach in vessel, perivascular fibrillar collagen exposed). Nevertheless, we conclude that both in subendothelium and in the extracellular matrices the major binding site for von Willebrand factor is not collagen.

There is an interesting difference in inhibition between platelet adherence to the endothelial cell matrix and to the smooth muscle cell matrix. CLB-RAg 35 , the antibody that blocks the binding of von Willebrand factor to GPIb, inhibits 95\% of the adhesion to endothelial cell matrices while only $75 \%$ of the adhesion to smooth muscle cell matrices is inhibited. Possible explanations for this inconsistency are $(a)$ that on smooth muscle cell matrices another type of interaction of von Willebrand factor with platelets is induced (GPIIbIIIa) or (b) that a part of the platelet adhesion to these matrices at the shear rate that was used is independent of von Willebrand factor.

von Willebrand factor binds strongly to collagen types I and III compared with other purified matrix proteins. When purified collagen types I and III are spread on glass coverslips and then exposed to flowing blood, platelets will rapidly adhere (29). The extracellular matrix of cultural human endothelial cells and smooth muscle cells contains a substantial amount of collagen type III $(36,37)$. One cannot but assume that the collagen molecules present in the extracellular matrix are involved in the interaction with other matrix proteins or with proteoglycans, and that the binding site for von Willebrand factor is shielded. 
To which matrix component does exogenous von Willebrand factor bind? Both Hormia et al. and Wagner et al. (15, 16) suggested fibronectin as the main candidate. Hormia et al. have used a protein overlay technique to show that ${ }^{125} \mathrm{I}$-fibronectin binds to von Willebrand factor. These results showed that von Willebrand factor is a major fibronectin-binding protein in endothelial cells, but this does not mean that fibronectin is the major von Willebrand factor binding protein. In our studies (Table II), there is hardly any binding of purified von Willebrand factor to purified fibronectin. However, it is possible that binding of only a few von Willebrand factor molecules is enough for optimal platelet adhesion. On the other hand there are other glycoproteins present in the vessel wall, e.g., thrombospondin, laminin, nidogen, and collagen type VIII, that are potential binding sites for von Willebrand factor. There are also different types of proteoglycans present in the vessel wall, and proteoglycans may also contribute to the interaction of von Willebrand factor with the vessel wall (38). Recently Rand et al. reported binding of von Willebrand factor to a $150-\mathrm{kD}$ protein in the vessel wall (39). The nature of this substance is unknown. Further studies are needed to clarify this important aspect of the adhesion of platelets to damaged vessels.

On the basis of the results presented in this paper and on the basis of previous fluorescence studies $(8,15,16)$, it can be concluded that collagen is not the primary binding site of von Willebrand factor in the vessel wall in the described system.

\section{Acknowledgments}

The authors thank Miss Marion Schiphorst, Mrs. Anne-Marie van der Hoeven, and Miss Hetty de Boer for their technical assistance, and Miss Annemiek Beijer and Miss Maeyken Hoeneveld for their secretarial assistance.

This study was supported by the Foundation for Medical Research (Fundamenteel Geneeskundig Onderzoek, FUNGO) grant 13-90-92.

\section{References}

1. Hovig, T., and H. Stormorken. 1974. Ultrastructural studies on the platelet plug formation in bleeding time wounds from normal individuals and patients with von Willebrand's disease. Acta Pathol. Microbiol. Scand. 248(Suppl.):105-122.

2. Mustard, J. F., M. A. Packham, and R. L. Kinlough-Rathbone. 1981. Mechanisms in thrombosis. In Haemostasis and Thrombosis. A. L. Bloom, D. P. Thomas, editors. Churchill Livingstone Inc., 503-526.

3. Ross, R., and J. A. Glomset. 1976. The pathogenesis of atherosclerosis. N. Engl. J. Med. 295:369-377, 420-425.

4. Tschopp, T. B., H. J. Weiss, and H. R. Baumgartner. 1974. Decreased adhesion of platelets to subendothelium in von Willebrand's disease. J. Lab. Clin. Med. 83:296-300.

5. Stel, H. V., K. S. Sakariassen, P. G. de Groot, J. A. van Mourik, and J. J. Sixma. 1985. The von Willebrand factor in the vessel wall mediates platelet adherence. Blood. 65:85-90.

6. Sakariassen, K. S., P. A. Bolhuis, and J. J. Sixma. 1979. Human blood platelet adhesion to artery subendothelium is mediated by factor VIII-von Willebrand factor bound to subendothelium. Nature (Lond.). 279:636-638.

7. Wagner, D. D., and V. Marder. 1983. Biosynthesis of von Willebrand protein by human endothelial cells. J. Biol. Chem. 258:20652067.
8. Rand, J. H., I. I. Sussman, R. E. Gordon, S. U. Shu, and V. Solomon. 1980. Localization of factor VIII-related antigen in human vascular subendothelium. Blood. 55:752-756.

9. Scott, D. M., B. Griffin, D. S. Pepper, and M. J. Barnes. 1981. The binding of purified Factor VIII/von Willebrand factor to collagen of differing type and form. Thromb. Res. 24:467-472.

10. Santoro, S. A. 1981. Adsorption of von Willebrand factor/Factor VIII by genetically distinct interstitial collagens. Thromb. Res. 21:689-693.

11. Santoro, S. A., and J. F. Cowan. 1982. Adsorption of von Willebrand factor by fibrillar collagen: implications concerning the adhesion of platelets to collagen. Collagen Relat. Res. 2:31-43.

12. Legrand, Y. J., A. Rodriguez-Zeballor, G. Kartalis, F. Fauvel, and J. P. Caen. 1978. Adsorption of Factor VIII-antigen activity complex by collagen. Thromb. Res. 13:909-911.

13. Santoro, S. A. 1983. Preferential binding of high molecular weight forms of von Willebrand factor to fibrillar collagen. Biochim. Biophys. Acta. 756:123-126.

14. Sixma, J. J., K. S. Sakariassen, H. V. Stel, W. P. M. Houdijk, D. W. in der Maur, R. J. Hamer, P. G. de Groot, and J. A. van Mourik. 1984. Functional domains on von Willebrand factor. Recognition of discrete tryptic fragments by monoclonal antibodies that inhibit interaction of von Willebrand factor with platelets and with collagen. $J$. Clin. Invest. 74:736-744.

15. Wagner, D. D., M. Urban-Pickering, and V. J. Marder. 1984. Von Willebrand protein binds to extracellular matrices independently of collagen. Proc. Natl. Acad. Sci. USA. 81:471-475.

16. Hormia, M., V. P. Lehto, and I. Virtanen. 1983. Factor VIIIrelated antigen. A pericellular matrix component of cultured human endothelial cells. Exp. Cell Res. 149:483-497.

17. Stel, H. V., K. S. Sakariassen, B. J. Scholte, E. C. I. Veerman, T. M. van der Kwast, P. G. de Groot, J. J. Sixma, and J. A. van Mourik. 1984. Characterization of 25 monoclonal antibodies to Factor VIII-von Willebrand factor. Relation between ristocetin induced platelet aggregation and platelet adherence to subendothelium. Blood. 63:1408-1516.

18. Jaffe, E. A., R. L. Nachman, C. G. Becker, and C. R. Minick. 1973. Culture of human endothelial cells derived from umbilical veins. Identification by morphological and immunological criteria. J. Clin. Invest. 52:2745-2756.

19. Willems, C., G. C. B. Astaldi, P. G. de Groot, M. C. Jansen, M. D. Gonsalves, W. P. Zeylemaker, J. A. van Mourik, and W. G. van Aken. 1982. Media, conditioned by cultured human vascular endothelial cells, inhibit the growth of vascular smooth muscle cells. Exp. Cell Res. 139:191-197.

20. Houdijk, W. P. M., P. G. de Groot, P. F. E. M. Nievelstein, K. S. Sakariassen, and J. J. Sixma. 1986. Von Willebrand factor and fibronectin but not thrombospondin are involved in platelet adhesion to subendothelium. Arteriosclerosis. 6:24-33.

21. Ross, R. 1971. The smooth muscle cell. II. Growth of smooth muscle in culture and formation of elastic fibers. J. Cell Biol. 50:172186.

22. Sakariassen, K. S., P. A. Bolhuis, and J. J. Sixma. 1980. Platelet adherence to subendothelium of human arteries in pulsatile and steady flow. Thromb. Res. 415:547-559.

23. Baumgartner, H. R. 1973. The role of blood flow in platelet adhesion, fibrin deposition and formation of mural thrombi. Microvasc. Res. 5:167-179.

24. Sakariassen, K. S., P. A. M. M. Aarts, P. G. de Groot, W. P. M. Houdijk, and J. J. Sixma. 1983. A perfusion chamber developed to investigate platelet interaction in flowing blood with human vessel wall cells, their extracellular matrix, and purified components. J. Lab. Clin. Med. 102:522-535.

25. A. Johnstone, and R. Thorpe, editors. 1982. Immunochemistry in Practice. Blackwell Scientific Publications Oxford, London, Edinburgh, Boston, Melbourne. 70-72. 
26. Van Mourik, J. A., and I. A. Mochtar. 1970. Purification of human antihemophilic factor (factor VIII) by gel chromatography. Biochim. Biophys. Acta. 221:677-679.

27. Fraker, P. J., and J. C. Speck. 1978. Protein and cell membrane iodinations with a sparingly soluble chloramide,1,3,4,6,-tetrachloro3f,6£-diphenyl glycolurol. Biochem. Biophys. Res. Commun. 80:849857.

28. Mumby, S. M., G. J. Raugi, and P. Bornstein. 1985. Interaction of thrombospondin with extracellular matrix proteins: selective binding to type V collagen. J. Cell Biol. 98:646-652.

29. Houdijk, W. P. M., K. S. Sakariassen, P. F. E. M. Nievelstein, and J. J. Sixma. 1985. Role of Factor VIII-von Willebrand factor and fibronectin in the interaction of platelets in flowing blood with monomeric and fibrillar human collagen types I and III. J. Clin. Invest. 75:531-540.

30. Laemmli, U. K. 1970. Cleavage of structural proteins during the assembly of the head of bacteriophage T4. Nature (Lond.). 227:680-685.

31. Towbin, H., T. Staehelin, and J. Gordon. 1979. Electrophoretic transfer of proteins from polyacrylamide gels to nitrocellulose sheets. Procedure and some applications. Proc. Natl. Acad. Sci. USA. 76:4350-4354.

32. Fujimoto, T., S. Ohara, and J. Hawiger. 1982. Thrombin-induced exposure and prostacyclin inhibition of the receptor for Factor
VIII/von Willebrand factor on human platelets. J. Clin. Invest. 69:6038-6041.

33. Ruggeri, Z. M., R. Bader, and L. De Marco. 1982. Glanzmann thrombasthenia deficient binding of von Willebrand factor to thrombin-stimulated platelets. Proc. Natl. Acad. Sci. USA. 79:6038-6041.

34. Ruggeri, Z. M., L. de Marco, L. Gatti, R. Bader, and R. R. Montgomery. 1983. Platelets have more than one binding site for von Willebrand factor. J. Clin. Invest. 72:1-12.

35. Verwey, C. L., C. J. M. de Vries, B. Distel, A. J. van Zonneveld, A. Geurts van Kessel, J. A. van Mourik, and H. Pannekoek. 1983. Construction of cDNA for human von Willebrand factor using antibody probes for colony-screening and mapping of the chromosomal gene. Nucleic Acid Res. 13:4699-4717.

36. Barnes, M. J., L. R. Morton, and C. J. Levene. 1978. Synthesis of interstitial collagens by pig aortic endothelial cells in culture. Biochem. Biophys. Res. Commun. 84:646-653.

37. Sage, H., E. Crough, and P. Bornstein. 1979. Collagen synthesis by bovine endothelial cells in culture. Biochemistry. 18:5433-5442.

38. Bockenstedt, P. L., J. Greenberg, and R. I. Handin. 1985. Isolation of a von Willebrand factor fragment with ristocetin-dependent-platelet binding activity using heparin sepharose. Thromb. Haemostasis. 54:59.

39. Rand, J. H., N. D. Patel, and B. J. Potter. 1986. Characterization of a non-collagenous binding site for von Willebrand factor in human vascular subendothelium. Blood. 68(Suppl.):324a. (Abstr.) 